\title{
INFÂNCIA: DESAPARECIMENTO OU METAMORFOSE?
}

\author{
Arnaldo Nogaro ${ }^{1}$ \\ Hildegard Susana Jung ${ }^{2}$ \\ Elaine Conte ${ }^{3}$
}

\section{Resumo}

O presente artigo dedica-se ao tema da infância. Resulta de pesquisa teórica de natureza qualitativa com o objetivo de problematizar o surgimento do conceito de infância e seu possível desaparecimento ou metamorfose no cenário contemporâneo. Fala-se do aparecimento da infância como um conceito criado a partir da modernidade e que estaria desaparecendo diante das transformações pelas quais passa a sociedade contemporânea. Crianças sempre existiram ao longo da história, no entanto, foram tratadas segundo os modelos sociais e as características de cada sociedade e época. Decorre daí o conceito de infância, que passa a ser interpretado e visto segundo a forma como as crianças são culturalmente percebidas. Refletir sobre a infância torna-se um mecanismo de interação profícuo para discutir a realidade das crianças na atualidade e assim entender qual é o papel da escola em um mundo de significados produzidos nas mediações e articulações sociais. O texto dá visibilidade à discussão da relação tensa entre adulto e criança, autoridade e autonomia, participação e imitação das crianças, que implica experiências com as diferenças entre crianças e adultos na cultura da circularidade digital, retomando e estimulando a construção conjunta no cotidiano escolar.

Palavras-chave: Crianças. Adultos. Infância. Escola.

\section{CHILDHOOD: DISAPPEARANCE OR METAMORPHOSIS?}

\begin{abstract}
This article is dedicated to the theme of childhood. It results from theoretical research of a qualitative nature with the objective of problematizing the emergence of the concept of childhood and its possible disappearance or metamorphosis in the contemporary scenario. There is talk of the emergence of childhood as a concept created from modernity and that it has been disappearing because of the transformations through which contemporary society is passing. Children have always existed throughout history, however, have been treated according to social models and the characteristics of each society and time. The concept of childhood then comes to be interpreted and seen in the way children are culturally perceived. Reflecting on childhood becomes a mechanism of fruitful interaction to discuss the reality of children today and thus understand the role of school in a world of meanings produced in social mediations and articulations. The text gives visibility to the discussion of the tense relationship between adult and child, authority and autonomy, participation and mimicking from part of children, which implies experiences with the differences between children and adults in the culture of digital circularity, retaking and stimulating the joint construction in school everyday.
\end{abstract}


Keywords: Children. Adults. Childhood. School.

\section{INFANCIA: ¿DESAPARICIÓN O METAMORFOSIS?}

\section{Resumen}

El presente artículo se dedica al tema de la infancia. Resulta de investigación teórica de naturaleza cualitativa con el objetivo de problematizar el surgimiento del concepto de infancia y su posible desaparición o metamorfosis en el escenario contemporáneo. Se habla del aparecimiento de la infancia como un concepto creado a partir de la modernidad y que estaría desapareciendo ante las transformaciones por las cuales pasa la sociedad contemporánea. Niños siempre han existido a lo largo de la historia, sin embargo, han sido tratadas según los modelos sociales y las características de cada sociedad y época. Desde entonces, el concepto de infancia pasa a ser interpretado y visto según la forma como son percibidos culturalmente los niños. Reflexionar sobre la infancia resulta mecanismo proficuo para discutir la realidad de los niños en la actualidad y así entender cuál es el papel de la escuela en un mundo de significados producidos en las mediaciones y articulaciones sociales. El texto da visibilidad a la discusión de la tensa relación entre adulto y niño, autoridad y autonomía, participación e imitación de los niños, que implica experiencias con las distinciones entre niños y adultos en la cultura de la circularidad digital, retomando y estimulando la construcción conjunta en el cotidiano escolar.

Palabras clave: Niños. Adultos. Infancia. Escuela.

\section{INTRODUÇÃO}

Recentemente assistimos a um documentário denominado $\mathbf{O}$ começo da vida ${ }^{4}$. Trata-se de uma produção que percorre o mundo para demonstrar como os primeiros anos da vida de uma pessoa podem ser decisivos para toda a sua trajetória. Apresenta ainda a visão de especialistas sobre esta etapa da vida, assim como histórias de famílias de diferentes culturas e classes sociais. A questão levantada pelo documentário é saber como estamos lidando com a primeira infância. Para isso, são mostrados ainda vários fatores capazes de influenciar o desenvolvimento das crianças. Este documentário levou-nos a refletir sobre o que estamos fazendo com nossas crianças. A preocupação ganhou maior profundidade ao ler o livro de Sibilia (2012), no qual ela traça um panorama da criança hoje no universo doméstico e escolar, mostrando as contradições e inconsistência de nossa época e o conflito existente entre os interesses da criança, o que a escola e a família pensam e desejam.

Insistentemente nos perguntamos sobre onde chegaremos ou o que se espera do futuro. Qual o espaço para a escola na educação das crianças quando estas estão imersas e envolvidas inteiramente pelos artefatos tecnológico-midiáticos? Corea e Lewkowicz 
Artigo

doi: $10.20396 /$ rho.v18i3.8652022

(1999) ponderam que talvez tenhamos que aprender a ensinar sem educar e a pensar sem saber. Na fluidez do contexto contemporâneo impõe-se repensar a infância, os papeis da família, do professor e do estudante, na aposta de que a condição de ser criança implica a possibilidade de dizer e participar do mundo da vida como ator social.

Javeau (2005) estabelece uma distinção semântica entre os conceitos criança, infância (s) e crianças. No seu entendimento o termo criança tem sua conotação relacionada à psicologia, mais especificamente às fases do desenvolvimento. A infância é o segundo campo semântico que inscreve seu ponto de partida numa perspectiva demográfica. As crianças seria o terceiro campo, de conotação deliberadamente antropológica, como agrupamento de indivíduos, constituintes de um território, portadoras de um conjunto de direitos, com suas linguagens, traços culturais e formas de ação cujo nível de escolaridade é denominado Educação Infantil (JAVEAU, 2005). A distinção semântica se torna importante, embora, ao longo do texto isso não seja objeto de nossa preocupação. Vamos tratar de criança e crianças como sinônimos. A infância tem seu sentido específico e o abordaremos na sequência.

A infância é uma fase da vida do ser humano repleta de desafios, experiências, curiosidades, conhecimento a respeito do mundo, época de fazer contato com novas pessoas, socializar-se, brincar, divertir-se. Porém, nem sempre as crianças têm esses direitos reconhecidos. Inserida na ausência do reconhecimento da infância como uma fase essencial no desenvolvimento humano, a Educação Infantil também foi negligenciada. Graças aos estudiosos e defensores da área é que a infância, o ensino e o cuidado às crianças passaram a ser reconhecidos, inclusive conquistando legislações próprias que amparam seu bem-estar, progresso e desenvolvimento integral (JAVEAU, 2005).

Para atingirmos o objetivo a que nos propomos, estruturamos o texto apresentando inicialmente elementos a respeito da produção discursiva sobre a infância. Num segundo momento discorremos sobre o resgate da infância e como terceira etapa referenciamos ideias que prognosticam seu possível desaparecimento. Por fim, abordamos alguns dilemas enfrentados pela infância em tempos contemporâneos.

\section{A PRODUÇÃO DISCURSIVA ACERCA DA INFÂNCIA}

Constatamos, em período recente, um contingente significativo de estudos sobre a infância, o que faz Pinto e Sarmento (1997) abordá-los como epistemologia da infância. Mesmo que haja interesse em assumir a causa das crianças, estes estudos revelam que há certa colonização ou produção discursiva dos adultos sobre as crianças, mesmo que alguns teóricos advoguem em favor de uma epistemologia própria. Ao pensar a infância, há que ponderar o contexto ou o lugar que as crianças ocupam em determinada sociedade. A descontextualização gera a idealização e a produção de um discurso vazio em abarcar as 
dimensões, complexidades e alteridade da infância. É necessário levar em conta o mundo da vida das crianças. "Parece por isso indispensável considerar na investigação da infância como categoria social a multivariedade sincrônica dos níveis e fatores que colocam cada criança numa posição específica na estrutura social" (PINTO; SARMENTO, 1997, p. 7).

A criança sempre existiu, porém, a concepção de infância, de acordo com Ariès (1981), é recente, pois teve sua invenção na modernidade. Uma nova maneira de compreender a criança é então inaugurada e a escola desempenha papel fundamental no sentido da afirmação dos direitos da criança à educação, à cultura e à sociabilidade. Os discursos sobre as necessidades das crianças adquirem novas representações de acordo com o tempo social vivido, constituindo uma vontade de saber sobre a infância e sobre a maneira de lidar com ela.

Segundo Ghirardelli Junior (2000), Ariès trata da noção de infância como algo que vai sendo montado, criado a partir das novas formas de falar, de sentir dos adultos, em relação ao que fazer com as crianças. "A noção de infância é uma noção moderna. A pósmodernidade não precisa dessa noção. A educação pós-moderna, então, pode finalmente fazer educação sem ter de perguntar se Pinóquio, por ter cabeça de pau, deve ou não estar na escola" (GHIRARDELLI JUNIOR, 2000, p. 57). Isso leva a considerar que em uma perspectiva histórica a ideia de infância ganha um lugar definido na modernidade. Já para o olhar que tem como base a teorização em numa perspectiva pós-moderna, a infância pode estar mais envolvida com uma ideia de movimento cultural do que de fixação antecipada de uma categoria. Então, é possível identificar que estas concepções são paradoxais, pois enquanto em uma a infância é inaugurada a partir da lógica pontual de ordem, de classificação, de estabelecimento de um lugar no mundo, na outra, a partir de uma noção ampla de cultura, a infância torna-se plural, tendo a diferença como ponto de partida, opondo-se a categorizações e a pré-conceitos.

O conceito de infância é muito difuso na história, não decidido pela natureza humana, mas pela cultura. Para entendê-lo deve-se vê-lo como construção social que não pode ser dissociada de outras variáveis da análise social. Independentemente da compreensão que se tenha da infância ao longo da história, o que é certo é que ela, do ponto de vista dos adultos, necessitava de certo tipo de educação. Nesse sentido, Barbosa (2000, p. 104) explica: "A fim de que esse projeto pudesse ser realizado, foram construídos espaços educacionais específicos para as crianças pequenas e prescritos modos distintos de intervenção através de diversas pedagogias".

No entendimento de Kohan (2010, p. 126), a tarefa de escrever sobre a infância extrapola o âmbito da língua, tornando-se um ato político, "[...] uma manifestação de resistência a uma forma de relação conosco mesmos e com aquilo chamado de humanidade: assim, o desafio ao escrever a infância é deixar-se escrever por ela". De acordo com o autor, a escrita torna-se política porque funciona como um testemunho e, ao 
Artigo

doi: $10.20396 /$ rho.v18i3.8652022

mesmo tempo, um esquecimento. Além disso, recupera um outro do humano, esse Lyotard (1986) chamará de infância.

Kohan (2010) fala de uma infância invisível. Onde estaria ela? Quem integraria esta infância? Quando refletimos sobre o desaparecimento da infância ou a criação de outra infância diferente da clássica, que perdurou por dois séculos, nela abrigamos todos os sujeitos que de fato pertencem à infância? Quem fica de fora? Quem está sendo esquecido? Há uma infância sobre a qual mais se silencia do que se fala hoje: a marginalizada, empobrecida, despida, com fome, de direitos negados.

Quando construímos um discurso ou teorizamos sobre a infância, de quem estamos falando? A que segmento social pertence? Há certo perigo de falar da infância sem definir de quem estamos falando, pois ela pode tornar-se uma categoria impessoal que serve para tudo e, ao mesmo tempo, para nada. Precisamos materializar, contextualizar, encarnar nossas falas para que elas não se tornem vazias de sentido. Na perspectiva de Kohan (2010), é preciso quando afirma que a tentativa de escrever sobre a infância mostra palavras de fundo inexplorado e impensado dos discursos que dizem conhecer a infância. Em suas palavras:

[...] se ainda consigo vencer aquele silêncio sublime que merece a infância, é no intuito de afirmar as palavras que tornem visível essa outra infância invisível e, a partir dessa nova visibilidade, permitam encontrar um novo lugar para a infância na palavra e no pensamento. (KOHAN, 2010, p. 128).

É necessário buscar um novo lugar para pensar sobre a infância e escrever acerca dela nos espaços educacionais. O mesmo autor afirma que é alto demais o preço que pagamos por esquecer a infância. Ele nos leva a refletir sobre o que será de nós como país ao condenar grande contingente de crianças à exclusão e tirar-lhe qualquer perspectiva de futuro. E pondera: "A pergunta que não podemos calar é se acaso é possível sair do esquecimento da infância em alguma forma de vida - e de morte - social ainda por inventar" (KOHAN, 2010, p. 133). Que modelo social nos permitiria criar alguma perspectiva e semear a esperança ao exército de abandonados na mais tenra idade? Quando tratamos da infância temos mais perguntas do que respostas, por isso, o autor referido fala da dificuldade de pronunciar-se a este respeito, pois todo escrever sobre é uma forma de captura pelo e no texto (KOHAN, 2010). Ao definirmos um território, delimitamos fronteiras e desconsideramos a alteridade de distintas experiências, os estranhamentos da vida social e do outro sobre o qual não vamos dizer. Falamos da infância e deixamos do outro lado a infantia (o que não se fala). Esse é o dilema que enfrentamos, mas que sempre é melhor do que silenciar ou omitir-se.

Desta forma, faz-se necessário investigar e refletir a respeito da história da infância e do direito de as crianças receberem um tratamento digno e educação de qualidade em amplos aspectos. Do ponto de vista histórico, as crianças aparecem como categoria quando se começa a separar as pessoas umas das outras e criam-se categorias dentre elas. Antes da 
modernidade e desta estratificação, as pessoas viviam nos mesmos ambientes, usufruíam das mesmas condições e partilhavam dos mesmos acontecimentos, independentemente de sua idade, "[...] a vida em família até o século XVIII era vivida em público [...] não havia privacidade de seus membros, até mesmo no tocante à educação das crianças. Tudo ocorria no movimento de uma vida coletiva e as famílias conjugais se diluíam nesse meio" (ANDRADE, 2010, p. 49). De acordo com a autora, as funções educativas eram societárias se estendiam desde o processo de socialização até o ensino formal.

Mudanças importantes ocorrem, ainda conforme Andrade (2010) e a infância começa a aparecer fortemente marcada pelo desejo de privacidade. O espaço coletivo começa a tornar-se privado, passando para a intimidade da família, reduzindo-se a sociabilidade ampla. As crianças passam a ser responsabilidade dos pais. A esfera do público torna-se privada. A criança nasce socialmente como um ser dependente e frágil, ignorante e vazio que precisa que alguém o oriente. Transformações nos valores processam-se, especialmente pela influência religiosa, e surge um sentimento moralista em relação à infância que é separada de outros segmentos e torna-se objeto de estudo, instrução e escolarização.

Até este período não havia qualquer restrição na linguagem usada e nas práticas do cotidiano. A exigência de ler e escrever tornou-se um critério para a separação das crianças e dos adultos. "E foram separados porque passou a ser essencial na sua cultura que eles aprendessem a ler e a escrever, e a ser o tipo de pessoa que uma cultura letrada exigia" (POSTMAN, 1999, p. 51). Esta separação vai se refletir em vários aspectos da vida, por exemplo, os adultos estariam de posse de uma linguagem e conhecimentos que não eram adequados às crianças ou que estaria restrita a eles. Estes segredos seriam revelados à medida em que a criança crescia e tornava-se adulta.

A ideia de infância proveniente de Platão (1996) e Agostinho (1997) descreve a criança como um ser em estado primitivo, com a ausência da linguagem e da razão, cabendo domesticá-la e moldá-la pelas regras sociais. A educação tradicional encontra respaldo nesta concepção para desenvolver práticas disciplinares e de governabilidade adotadas nos educandários. Essa compreensão de infância dá origem a orientações específicas a respeito do comportamento e da conduta que deveriam adotar as crianças. Surgem os primeiros escritos sobre boas maneiras e inicia-se um processo de disciplinamento e controle sobre a vida e as ações dos infantes. Aparece o sentimento de vergonha em decorrência do mau comportamento ou da conduta inadequada às regras estabelecidas, de como portar-se em público. Como explica Andrade (2010, p. 58), “o interesse pela infância propagado pela modernidade inaugura, num certo sentido, a preocupação com a criança e sua formação, porém o objetivo não era a criança em si, mas o adulto de amanhã". A partir do reconhecimento como fase da imaturidade, legitima-se um discurso que descreve a infância como uma etapa do desenvolvimento humano. Neste período, a criança é caracterizada como um ser frágil e que depende do adulto, devendo 
receber educação e disciplina de modo a desenvolver plenamente suas potencialidades, inclusive a razão.

Ao abordar o conceito de infância, faz-se necessário também refletir a respeito do conceito de criança. Esses dois termos não podem ser considerados como sinônimos, embora estejam intimamente relacionados. Quanto ao conceito de infância, Qvortrup (2010, p. 634-635) revela que em

[...] linguagem coloquial e no discurso científico, a infância é comumente caracterizada como um período. O período que temos em mente é relativo ao indivíduo e pode ter várias durações; de qualquer forma deve ser o período de tempo que demarca o começo e o fim da infância individual de uma pessoa.

O interesse por esses conceitos e em relação aos serviços para a infância asseverouse no momento em que o reconhecimento e a participação desses sujeitos torna-se um problema social. Nesse sentido, Pinto e Sarmento (1997) afirmam que as crianças são tanto mais consideradas quanto mais diminui o seu peso no conjunto da população. Isso talvez explique a razão de tantos estudos, pesquisas e teorizações sobre a infância nas últimas décadas, especialmente em países onde se evidencia um crescimento vegetativo negativo e diminuição considerável do número de filhos por família. Mas este não é o único fator, pois soma-se a ele a angustiante situação dos países nos quais há conflitos armados, guerras civis e miséria que flagelam e condenam o futuro de milhões de crianças ou mesmo as dizimam.

De qualquer forma, esclarecemos que a infância, fase em que a criança começa a inserir-se na sociedade, não tem um período pré-determinado para iniciar ou terminar, porém, desde quando nasce o indivíduo já se torna um ser social, pensante e ativo em uma sociedade em constante transformação. Assim, é possível caracterizar a criança como o sujeito socializador e a infância como uma fase em que este ser estará envolvido no fazer social. Então, neste caso, a infância não pode ser considerada apenas como uma preparação para a vida em sociedade ou uma antecipação da fase adulta, pois ela já está no contexto do desenvolvimento social e cultural. No entendimento de Qvortrup (2010, p. 637), "a infância existe enquanto um espaço social para receber qualquer criança nascida e para incluí-la - para o que der e vier - por todo o período da sua infância. Quando essa criança crescer e se tornar um adulto, a sua infância terá chegado ao fim”. Entretanto, o próprio autor complementa que, enquanto categoria, a infância continua existindo e recebe novas gerações de crianças.

Os maus tratos ou penalização a crianças são comuns ao longo da história, não é um privilégio de nossa época. Em alguns aspectos, hoje conseguimos certa proteção para elas. Postman (1999) argumenta que até 1814 não era considerado crime roubar uma criança para vendê-la como escravo ou para outra finalidade. A revolução industrial é o exemplo típico de uso de trabalho infantil e de desrespeito aos princípios de humanização. 
Com respeito ao tema da construção da história da infância, Sibilia (2012, p. 107) ressalta que esta fase foi importante para que hoje tivéssemos o entendimento de que as crianças nem sempre foram assim ou pelo menos, como as conhecemos na modernidade: "[...] em outras épocas havia meras crias humanas [...]", além disso, dependendo das condições físicas em que nasciam eram sacrificadas, sendo-lhes negado o direto a vida.

A ideia da criança como propriedade dos pais vem de longa data e perdura ainda hoje em muitas culturas, embora já tenhamos a definição de normas e critérios que delimitam os poderes paternos e maternos. Postman (1999, p. 70) enfatiza que pais habitualmente tratavam seus filhos não só como propriedade privada, podendo fazer o que quisessem "[...] com eles, mas também como servos cujo bem-estar era sacrificável no interesse da sobrevivência familiar".

Em alguns países, as condições da infância melhoraram com o entendimento de que, como ser social, a criança deveria ser respeitada, também, como um ser individual. O documento norteador do Ministério da Educação (MEC) brasileiro para o programa Alfabetização na Idade Certa esclarece que há três elementos essenciais que precisam ser levados em conta para compreender o percurso da infância e das crianças:

[...] a individualidade surge como elemento essencial na contemporaneidade; [...] a institucionalização familiar e escolar se tornaram os ancoradouros da infância e para as crianças; e, por fim, nos dias atuais a infância passou a ser reconhecida como uma geração que é parte da estrutura social, e as crianças, como atores sociais. (BRASIL, 2015, p. 10).

Da mesma forma, não se pode falar em infância sem relembrar a história da Pedagogia, que marca o início dos estudos sobre esta fase da vida do ser humano. Segundo Cambi (1999, p. 387), no "[...] curso do século XIX foram ora as ciências humanas ora as instituições educativas burguesas que puseram cada vez mais no centro da pedagogia a criança, assumida na sua especificidade psicológica e na sua função social”. Dessa maneira, a infância foi diferenciada da vida adulta, entendida como um processo

[...] evolutivo complexo e conflituoso, emotivo e cognitivo, portadora, porém, de valores próprios e exemplares: da fantasia à igualdade, à comunicação. Assim, a criança tornou-se o sujeito educativo por excelência, reclamando uma rearticulação das instituições educativas. (CAMBI, 1999, p. 387).

Entende-se que é nessa fase que se desenvolve o germe da personalidade humana. $\mathrm{O}$ processo de construção da concepção de infância avança e parte das fundamentações teóricas e práticas de grandes estudiosos, como Comênio, Rousseau, Pestalozzi, Decroly, Montessori, dentre outros. Gradativamente, passa a ser mais discutida por estudiosos da área da Pedagogia, Psicologia, Sociologia, etc., tentando entender as necessidades fundamentais desta faixa etária e pesquisar mais profundamente o complexo mundo infantil. Quanto à infância e sua complexidade, Pinheiro (2008, p. 15-16) afirma que, pese a toda a discussão que a temática suscita a partir do século XVIII, o assunto ainda 
[...] se apresenta como um tema complexo, que exige, ao longo do tempo, ressignificações através da colaboração de várias abordagens, como: o campo orgânico, psicológico, antropológico, social e educacional que atualmente definem a criança numa perspectiva integral.

Sob o ponto de vista antropológico, foi a partir da década de 1980 que a infância começou a ser analisada e estudada com mais intensidade. Segundo Friedmann (2015, p. 38) em meados da década de 1980 surgiu o interesse pela infância: "A grande diferença entre os grupos infantis e outros grupos é que as crianças estão em permanente desenvolvimento, motivo pelo qual sua observação, sua escuta e seu conhecimento tornamse muito mais complexos e desafiadores". A autora explica que, a partir dessa época, as pesquisas e os pesquisadores passam a entender que a infância comporta uma linguagem própria e uma cultura própria. Dessa maneira, os estudos demonstram que este público também possui voz, peculiaridades, necessidades e diferentes interesses, os quais podem não ser sempre iguais, dependendo do contexto no qual ocorre o seu desenvolvimento.

Segundo estudiosos como Muniz, as concepções de infância começaram a mudar depois do livro Emílio, de Jean-Jacques Rousseau, no qual o autor traz as bases daquilo que concebe como sendo um projeto pedagógico, mostrando a influência da escola na história da infância.

[As] ideias de Rousseau a respeito da educação de crianças e de seu lugar na sociedade vieram a influenciar a pedagogia, e seus reflexos são percebidos ainda hoje. Nesse livro, Rousseau inaugura uma noção de infância que vai marcar e caracterizar essa fase da vida do homem. (MUNIZ, 1999, p. 245).

Sobre a importância de reconhecer a infância como uma fase essencial ao desenvolvimento humano, Rousseau (1995, p. 10) afirma que se "[...] o homem nascesse grande e forte, seu porte e sua força seriam inúteis até que ele tivesse aprendido a deles servir-se. Ser-lhe-iam prejudiciais, impedindo os outros de pensar em assisti-lo". Assim, dizia, estaria abandonado, morreria sem conhecer as suas necessidades essenciais, e a raça humana pereceria se a vida do homem não começasse sendo criança.

Sendo assim, a infância precisa ser marcada por diferentes experiências sensoriais, motoras, afetivas, que possam ser significativas para seu desenvolvimento, uma vez que, viver esta fase da vida, significa estar desfrutando da sua natureza humana, lembrando-se sempre de que a criança é um ser ativo, que compõe a sociedade desde seu nascimento. Para Kohan (2010, p. 134), a infância “[...] é uma faculdade que nomeia algo que já é, mas sem ser ainda algo, um espanto que introduz no mundo do que é, aquilo que ainda não pode ser identificado e permite qualquer diferenciação".

Ainda Rousseau (1995, p. 6) afirmava que "eles procuram sempre o homem na criança, sem pensar no que esta é antes de ser homem." Com esta afirmação, buscava explicar que a infância tem um significado próprio na construção do ser humano, marcado por esta fase tão relevante e repleta de imaginações e brincadeiras de faz-de-conta, que 
Artigo

doi: 10.20396/rho.v18i3.8652022

refletem no mundo adulto e que auxiliam na formação de suas opiniões e ações mais tarde em sua vida. Mas esta parece ser uma ideia que começa a ser questionada por teóricos que levantam hipóteses de um possível desaparecimento da infância.

No pensar de Ghirardelli Junior (2000), no início do século XIX, a infância já aparece como algo obtido por construção histórica e sociocultural que a entrelaça com a cidade e a escola, bem como com as questões históricas das crianças expostas a vulnerabilidade social e subordinadas a interesses econômicos. Até então, os saberes constituídos sobre a infância priorizavam mais as questões legais e normativas das crianças do que a infância a partir do viés da própria construção dos mundos sociais e culturais da infância (FARIA; DEMARTINI; PRADO, 2005). "Recorrendo novamente a Sarmento, olhar a infância e não apenas sobre ela exige $o$ descentramento do olhar do adulto como condição essencial para perceber a criança." (FARIA; DEMARTINI; PRADO, 2005, p. 29, grifos dos autores). No entendimento de Sibilia (2012), para que houvesse escola, tinha que haver crianças; por isso, diante da necessidade histórica de realizar o projeto modernizador anunciado pelas revoluções científicas, industriais e democráticas, foi preciso inventar as duas.

$\mathrm{O}$ aparecimento da infância tem seu sentido e faz parte de uma lógica na qual o segmento crianças se diferencia dos adultos. Se continuassem sabendo as mesmas coisas, partilhando do mesmo status, não haveria razão para criar outra categoria, algo diferente como a infância. No momento em que se reconheceu que havia algo diferente e que indivíduos participavam de outra condição, surge um novo grupo e outro segmento com uma nova identidade e características peculiares. E aqui se inserem as tecnologias e a própria escola, pois elas vão se encarregar de levar a informação e o conhecimento que o adulto possui para a criança. Com a disseminação maciça das novas mídias e o acesso a diferentes plataformas de dados, hoje se questiona o papel da escola ou, no mínimo, discute-se sua função: "Resta-nos, então, crianças que confiam, não na autoridade do adulto, mas em notícias vindas de parte nenhuma. Resta-nos crianças que recebem respostas a perguntas que nunca fizeram. Em resumo não nos resta mais nenhuma criança" (POSTMAN, 1999, p. 104).

Esta parece ser uma questão que emerge nas últimas décadas e que ressignifica pontos de vista, põe em suspeição o trabalho do professor e o seu conhecimento. As crianças estão imersas em outra condição que lhe dá um status diferenciado daquele anterior. Em certos aspectos, elas usufruem as mesmas condições dos adultos, o que leva ao repensar do conceito de infância. Como exemplo, Postman (1999) cita a vergonha. Para ele, a ideia de vergonha se dilui e dissipa, pois ela só pode existir quando há o segredo e a proibição. Quando as crianças não possuem mais certas proibições, segredos e tabus são revelados, a vergonha desaparece. Ela é algo próprio da infância que está excluída de certos saberes e práticas, e quando estes passam a ser seus, a vergonha não mais existe. $\mathrm{O}$ poder e a autoridade dos adultos também entram em cheque, pois as crianças vão saber e 
conhecer tanto quanto eles. "Pois é, não há mistérios obscuros e fugidios para os adultos ocultarem das crianças e só revelarem quando acharem necessário, seguro e adequado, então sem dúvida a linha divisória entre adultos e crianças torna-se perigosamente tênue" (POSTMAN, 1999, p. 101).

Diante disso nos perguntamos: se despejamos uma quantidade de material adulto sobre as crianças, como elas sobreviverão? Qual a implicação disso para seu desenvolvimento? Postman (1999) alerta que preservar as crianças de certos conhecimentos e práticas pode ser um mecanismo saudável de protegê-las e contribuir com sua saúde física e mental. Por isso há que existir um controle em relação ao acesso livre à televisão e às Tecnologias da Informação e Comunicação - TIC. Elas abominam qualquer diferenciação, dão livre acesso e fazem parecer tudo isso como algo normal independente da capacidade, da condição ou da maturidade de cada ser humano. A linguagem é um exemplo típico. As crianças hoje utilizam termos e expressões que os adultos utilizam e poucos consideram isso inadequado, mesmo que sejam ofensivas ou de baixo calão. Para Postman (1999), parece que estamos retornando ao século catorze quando nenhuma palavra era considerada imprópria no vocabulário de qualquer criança ou jovem.

\section{DESAPARECIMENTO DA INFÂNCIA?}

Postman (1999) externa sua percepção a respeito do desaparecimento da infância. Para ele é uma invenção da Renascença, talvez a mais humanista que está se esvaindo. Segundo apregoa, é perceptível que a "[...] linha divisória entre a infância e a idade adulta está se apagando rapidamente [...]. O que não é tão bem entendido é, em primeiro lugar, de onde vem a infância e, ainda menos, por que estaria desaparecendo." (POSTMAN, 1999, p. 12). O autor afirma que a prensa tipográfica criou a infância e que a mídia eletrônica a faz desaparecer. Como reagir a isso? Ele mesmo não tem respostas. Sente-se paralisado frente a este movimento: "Ter que ficar parado à espera enquanto o charme, a maleabilidade, a inocência e a curiosidade das crianças se degradam e depois se transfiguram nos traços medíocres de pseudo-adultos é doloroso, desconcertante e, sobretudo, triste." (POSTMAN, 1999, p. 13). Ainda, nesse sentido, reforça que "[...] depois da prensa tipográfica, os jovens teriam de se tornar adultos e, para isso, teriam de aprender a ler, entrar no mundo da tipografia. E para realizar isso precisariam de educação. Portanto, a civilização europeia inventou as escolas" (POSTMAN, 1999, p. 50). A escola passa a ser uma necessidade.

O desaparecimento ou morte da infância convive com uma concepção oposta que defende o surgimento de uma infância diferente. Estamos convivendo com esta dicotomia que, na verdade, revela que há uma ressignificação na concepção de infância, uma espécie de transição de modelos. A concepção predominante nos últimos dois séculos cede lugar a uma que convive com as tensões da contemporaneidade. No entender de Marín-Díaz 
Artigo

doi: $10.20396 /$ rho.v18i3.8652022

(2010, p. 195), as discussões entre uma contra perspectiva tiveram uma consequência particularmente significativa: "[...] a consolidação de um campo discursivo sobre a infância e, com ele, a produção de uma quimera infantil, uma forma de subjetividade na qual se combinam os mais heterogêneos, incongruentes e diversos elementos e características que atribuímos às crianças".

Postman (1999) responsabiliza a mídia pelo desaparecimento da infância. Por sua vez, outros autores afirmam que cada vez mais se definem novas fronteiras entre o mundo adulto e o infantil fazendo com que permaneçam distintos e distantes cada vez mais. "A diferença que é condição de toda e qualquer diferença. Isso é a infância." (KOHAN, 2010, p. 133). Os argumentos de que a infância sucumbe e se hibridiza com o mundo adulto passam a ser questionados. Na visão de Marín-Díaz (2010), estaria acontecendo uma ruptura cultural sem precedentes entre o mundo adulto e o infantil da qual sai beneficiada a infância, até agora fortemente controlada pelos adultos. Assim,

\footnotetext{
As crianças trariam consigo conhecimentos e habilidades inatas, as quais lhes permitem agir diante das mídias com certa flexibilidade e frugalidade espontânea, com sua sede de aprender que, talvez, se libera automaticamente quando entram em contato com as novas tecnologias. (MARÍN-DÍAZ, 2010, p. 197).
}

Embora a autora faça a leitura do que está acontecendo com as crianças, não estamos totalmente de acordo que haja a naturalização destes fenômenos, pois já existem estudos que apontam o impacto negativo das novas mídias e games. Que as crianças se familiarizam mais facilmente com as tecnologias digitais é verdade, porém, temos que manter o olhar crítico para não legitimarmos situações que provoquem prejuízos e que levem a uma cegueira em relação a aspectos menos benéficos em nome da inovação.

Postman (1999) analisa a participação de crianças em competições e jogos. Ele demonstra que estes se tornaram mecanismos de disputa e profissionalização, próprios dos adultos. Isso demonstra que a singularidade das crianças está desaparecendo. O brincar que é algo identificado com a infância, próprio das crianças assume austeridade e pragmatismo. "O que temos aqui é o surgimento da ideia de que não se deve brincar só por brincar, mas brincar com algum propósito externo, como renome, dinheiro, condicionamento físico, ascensão social, orgulho nacional." (POSTMAN, 1999, p. 145). Desaparece um dos aspectos mais agradáveis da vida que é o lúdico, o brincar sem compromisso, pelo prazer estético, pela alegria espontânea. O mundo do adulto contaminou o infantil, tirou-lhe a beleza e a pureza. Martins Filho (2011, p. 92) é enfático: as crianças estão perdendo a infância, e, sobretudo nas classes mais altas, pois, “[...] os pais, desde os primeiros momentos querem preparar seus rebentos para ser competitivos e ter sucesso na futura vida de trabalho, exigindo deles comportamentos totalmente adultos, esquecendo-se de suas necessidades de fantasia e descanso". Será que quando adultos somos tão felizes a ponto de querermos que as crianças cheguem depressa a esta etapa da vida? 
Pinto e Sarmento (1997) referem-se a alguns paradoxos da sociedade. Citamos alguns a título de exemplo. Os adultos desejam e gostam de crianças, mas cada vez menos produzem crianças; os adultos acreditam que é bom os pais estarem próximos das crianças, mas no cotidiano, cada vez estão mais distantes; valoriza-se a espontaneidade das crianças, mas as submetem a regras e disciplina austera, etc. Estes e outros paradoxos levantam dúvidas a respeito daquilo que a sociedade contemporânea quer e espera da infância.

Marín-Díaz (2010, p. 205) ressalta que hoje possuímos sentimentos contraditórios em relação à infância em quatro grandes eixos: criminalidade, sexualidade, trabalho e educação, que produzem um campo discursivo muito particular na tentativa de incorporar e naturalizar, ampla e massivamente, características atribuídas à infância, por vezes as da figura clássica, por vezes as da liberal: "Não se pode negar que ao se pensar hoje na infância passam muitos sentimentos e imagens contraditórios pelas nossas mentes: ternura, proteção e cuidado surgem ante a imagem de inocência, fragilidade e ignorância que as crianças parecem comportar naturalmente". Entretanto, o temor e até a impotência também irrompem em nossas mentes "[...] quando encaramos o que parece ser o rosto cru e rude de uma infância muito esperta, vivaz, maliciosa, selvagem e até perigosa, essa que reconhecemos nas reportagens e noticiários, como vinculada aos nossos maiores pesadelos de decomposição e risco social" (MARÍN-DÍAZ, 2010, p. 205).

Postman (1999) conclui sua obra deixando a dúvida a respeito de quais pais serão capazes de resistir a todo o espírito de uma época e de uma cultura instalada. Afirma que não serão muitos que estão dispostos a passar trabalho para proteger seus filhos para que tenham uma infância e se colocarem no contra discurso existente. Aqueles que tomarão a decisão de fazê-lo ajudarão a manter viva a tradição humanista. Transcrevemos suas frases finais por serem profundas e representarem um apelo. "Não é concebível que nossa cultura esqueça que precisa de crianças. Mas está a caminho de esquecer que as crianças precisam de infância. Aqueles que insistem em lembrar prestam um nobre serviço" (POSTMAN, 1999, p. 167).

Acreditamos que uma forma de fazer o enfrentamento da questão é denunciando e refletindo a respeito do quadro que se encontram nossas crianças. Quanto mais disseminarmos nossa reflexão, mais consciência temos da possibilidade de criar e com isso fazer um chamamento público em favor da transformação desta realidade. Segundo Kramer (1995, p. 271-272),

[as] crianças são sujeitos sociais e históricos marcados pelas condições da sociedade em que vivemos. A criança não é filhote do homem, ser em maturação biológica; ela não se resume a ser alguém que não é, mas que se tornará (adulto, no dia em que deixar de ser criança!).

Corroborando com esta concepção, Ferreira $(2004$, p. 58) defende que a crianças não apenas reproduzem o mundo adulto, mas “[...] o reconstroem e ressignificam através 
de múltiplas e complexas interações com os pares, permite mostrá-las não só como autoras das suas próprias infâncias mas também como atores sociais com interesses e modos de pensar, agir e sentir específicos e comuns [...]".

Tendo seu próprio modo de conceber o mundo que as cerca, as crianças se definem como seres sociais, que produzem sua própria cultura e que são capazes de mostrar aos adultos elementos que vão além do que conseguem ver. Além disso, cada criança nasce com uma bagagem genética e adquire uma cultura que precisa ser respeitada. Friedmann (2015, p. 39) afirma que compreender "[...] a complexidade do ser humano e saber que suas raízes e as bases de sua formação acontecem já desde o ventre materno e se prolongam de forma muito intensa e fundante nos primeiros anos de vida é fundamental para o desafio de educadores", bem como para instituições que acolhem crianças.

Partindo do princípio de que a criança é um ser pensante e pode ser atuante na sociedade, que possui seus próprios direitos e deveres, o conceito de infância volta-se para o ser criança em sua totalidade, instituindo sua construção integral como ser humano na sociedade e também na escola de Educação Infantil que frequenta ou irá frequentar. Com relação ao tema, Bona (2010, p. 25) entende que "A Constituição Federal de 1988 traz um capítulo que reconhece todos os direitos básicos para todas as crianças, adotando, portanto, o princípio da universalidade, bem como sua condição especial de pessoa em desenvolvimento".

Ainda, verifica-se no Referencial Curricular Nacional para a Educação Infantil (BRASIL, 1998, p. 21) que as "[...] crianças possuem uma natureza singular, que as caracteriza como seres que sentem e pensam o mundo de um jeito muito próprio". Com isto, efetiva-se o fato de que hoje, na sociedade, a criança precisa ser respeitada e valorizada dentro de suas potencialidades, nas capacidades humanas de se comunicar, vivenciar experiências, aprender, interagir, criar, brincar, e ainda, ensinar os adultos o real sentido de viver em sociedade.

\section{DILEMAS DA INFÂNCIA NA SOCIEDADE DO PRESENTE: DESAPARECIMENTO OU METAMORFOSE?}

Sibilia (2012) traça um panorama da condição contemporânea e demonstra as transformações que estão se processando em diferentes frentes, instituições e indivíduos. Em suas prospecções alerta para o desaparecimento da infância em decorrência das mudanças que estão ocorrendo nas relações e nas atitudes das pessoas, sejam adultos ou crianças. De acordo com a pesquisadora supramencionada isto tem a ver com a crise dos mecanismos que sustentaram até hoje este conceito. "Como quer que seja, se ser criança já não é o que costumava ser, é possível que isso se leva ao atual esgotamento - ou, no 
Artigo

doi: $10.20396 /$ rho.v18i3.8652022

mínimo, à metamorfose - das instituições que sustentaram a infância nos últimos séculos, encabeçados pela família e pela escola" (SIBILIA, 2012, p. 205).

A criança enquanto alguém incompleto ou que precisa ser formado está desaparecendo, para dar lugar a consumidores da atualidade ou excluídos desse mesmo universo. Como consequência, entra em crise ou saem de cena as instituições responsáveis por cuidar de sua inocência. Por sua vez isso não significa que a criança fique imune ou protegida de suas fragilidades perante o mundo. Ela está submetida às mesmas vulnerabilidades dos adultos, o que nos deixa alertas ou apreensivos, no mínimo (SIBILIA, 2012). Assim, a criança de hoje não é um ser frágil e ingênuo: entende-se que ela já tem opinião e que já sabe, inclusive, consumir. "Não é mais um infante - cuja etimologia resulte, justamente, àquele que não fala - nem se supõe que deva ser formada para o futuro, mas é constantemente bombardeada por informações que lhe mostram como ser um garoto ou uma menina de hoje" (SIBILIA, 2012, p. 109).

Bujes (2010) alerta para os riscos que a infância está submetida. Estes são reais, eminentes e encontram-se no campo da prática, das políticas públicas e no plano do debate teórico. O silêncio colabora para que seus efeitos sejam maiores e atinjam os segmentos mais desassistidos da população. "Portanto, discutir tal problemática e admitir que ela se encontra marcada por todos estes cruzamentos supõe reconhecer também que eles contribuem para torná-la cada vez mais complexa." (BUJES, 2010, p. 159). Onde a autora localiza os riscos enfrentados pelas crianças ou aos quais estariam submetidas? Poderiam ser localizados em pontos tão díspares como o nível de escolarização dos pais, sua situação profissional, sua renda, a forma de estruturação familiar, o acesso a atendimento médico comunitário, a posição relativa da criança na constelação familiar, os hábitos de higiene familiar, as horas frente à TV, a frequência à escola, e tantos outros (BUJES, 2010). Esta condição desafia as famílias e as escolas e põe-nos em alerta, gera incertezas, provoca inquietação. Como educar? Como intervir? O que se pode fazer? Quais as saídas possíveis? Como agir nesse novo contexto? Estes questionamentos revelam nossas fraquezas e a crise de referência em que pais e educadores se encontram em função da perda de prerrogativas que cada um possuía na educação das crianças.

Em outras palavras, a infância está devassada. As crianças crescem sem a noção e o limite do bem e do mal, do certo e do errado, como consequência, desaparece a noção de moralidade. Não que se queira isolar as crianças dos traumas e das agruras a que a vida lhes proporciona, mas escancarar-lhe a mais dura realidade vai fazê-las cínicos e sem esperança. A mediação do adulto responsável é determinante. Martins Filho (2011, p. 22) pondera a respeito de que o vínculo, o afeto, o carinho, a presença dos pais, e nos primeiros anos principalmente das mães, parece ter muito a ver com a formação de uma "[...] psique mais forte e sólida e, sobretudo, com a sensação fundamental de bem-estar que gera o comportamento respeitoso, ético e colaborativo com os outros seres humanos e com a sociedade”. Deixá-las em contato direto com a violência, pornografia e a matéria-prima da 
Artigo

doi: $10.20396 /$ rho.v18i3.8652022

vida real demonstra que não são os melhores conselheiros. Resulta uma infância cínica e descrente, indiferente à política, à sociedade e às pessoas. Porém, não podemos esquecer que se estas cenas são produzidas e mostradas, em parte, revelam os elementos que constituem a vida adulta, o que no mínimo, deve levar-nos a pensar sobre ela. Parafraseando Postman (1999), o acesso ao fruto, antes escondido da informação adulta, faz com que sejam expulsas do jardim da infância.

Cada vez torna-se mais difícil educar uma criança, pois, algumas ideias sólidas que sustentavam esse processo se dissiparam levando com elas seus pilares e deixaram a força dos bordões de que nada pode ser sacrificado ou adiado em nome de um futuro ou do que virá. O que importa é o presente e o usufruir. Isto se constitui em um problema que, segundo Sibilia (2012, p. 113), assola diretamente a escola “[...] não só porque a criança atual se nega a assumir seu papel de pequeno adulto inacabado, mas porque nesse gesto são redefinidos também os papeis dos pais e dos professores".

Nessa redefinição de papeis, as crianças assumem o posto de quem toma decisões não só na escola, bem como no meio familiar, desautorizando e desconsiderando as ordens, apelos dos adultos, quando definem gostos, objetos a comprar, a consumir, pouco se importando com o que seus pais pensam ou quanto estão dispostos a gastar ou investir. Dentre os questionamentos de Sibilia (2012, p. 118), há um que chama a atenção e sobre o qual nos propomos a refletir: "[...] o que significaria educar, quando as subjetividades envolvidas nesse processo já não são as do professor e do aluno, mas as de consumidores imersos em plena era midiática?". Há algum tempo voltamos os olhos para a criança e para o comportamento infantil em nossa sociedade e nesse processo presenciamos depoimentos de muitos pais a respeito dos seus dilemas em relação à educação de seus filhos.

Os laços que unem professor e estudantes não existem mais em função dos regulamentos ou de normas, mas poderão ser reconstruídos em outras condições, não mais pautados pela moral, pela obrigatoriedade ou por que assim deve ser. Haverá que reconstruir os laços sob outros acordos, a partir das condições de cada um.

O que se propõe pensar que é que essa criança, que se definia em virtude de sua potencialidade para se tornar um cidadão como resultado da conjunção entre o filho - produzido pela família - e o aluno - moldado pela escola -, talvez seja hoje uma figura em extinção. (SIBILIA, 2012, p. 108).

Tal realidade e os dilemas enfrentados pela escola, em comparação ao meio familiar, se complexificam, pois, além de conviver com a insubordinação comportamental, disciplinar e a indiferença ao que ela propõe, incidem também as questões relacionadas à aprendizagem. Segundo Sibilia (2012, p. 120), tudo muda com demasiada rapidez, "[...] e o que antes tinha valor se depreciará em seguida; tanto os objetivos quanto os conhecimentos caem rapidamente em obsolescência e, então, não servem mais para nada". É o que Bauman $(2007$; 2008) denomina de liquidez da sociedade presente. 
O sociólogo polonês Bauman (2008) sinaliza como se constituem as atuais relações humanas na sociedade do consumo, pois de um lado, a mercadoria aparece como centro das práticas cotidianas, e de outro, uma constante orientação para que o modelo de conduta seja sempre articulado através do ato de consumir. O mercado passa a ser o novo articulador e modelador das relações humanas, ele é quem dita as normas que devem ser seguidas cotidianamente. $\mathrm{O}$ autor afirma que seu jogo é constituído por três regras: a primeira, que todo produto é vendável e visa ser consumido; a segunda, que esse consumo se vincula a satisfação de desejos; por fim, o valor a ser pago é dependente direto da confiabilidade da promessa de satisfação e intensidade de desejos. Assim, Bauman (2008, p. 18-19) conclui que, "[...] a sociedade dos consumidores se distingue por uma reconstrução das relações humanas a partir das relações entres os consumidores e os objetos de consumo."

Um dos sintomas da mudança civilizacional em curso pode ser percebido na sociedade do mercado. Para estar incluído e pertencer a ela deve-se consumir; para consumir há que se adquirir, para adquirir há que se ter capacidade (poder aquisitivo) para tanto, porém, o que se adquire na sociedade do consumo é fugaz, logo há que se empenhar esforço e recurso para adquirir novamente. "A vida dos consumidores é uma infinita sucessão de tentativas e erros" (BAUMAN, 2007, p. 110). Essa lógica mantém a sociedade do consumo na qual o sujeito está inserido num círculo vicioso em que para estar incluído e pertencer necessita-se aceitar e consumir, caso contrário, passa a não existir. É a inversão da lógica da vida na qual o fato de existir leva a consumir; para a sociedade do mercado a regra é consumir como condição para existir no mundo e isso implica em manter perene o sentimento dos desejos insatisfeitos, o que leva a mais consumo para sua realização. Essa realização, na prática, é uma pseudorrealização, pois está sempre em busca de concretizar objetivos irrealizáveis. "A sociedade de consumo tem por base a premissa de satisfazer os desejos humanos de uma forma que nenhuma sociedade do passado pode realizar ou sonhar. A promessa de satisfação, no entanto, só permanecerá sedutora enquanto o desejo continuar irrealizado [...]", pois a posse é a morte do desejo. (BAUMAN, 2007, p. 106).

\section{CONSIDERAÇÕES FINAIS}

A extinção gradativa do limite entre o que é do adulto e da criança não ocorre somente nas questões de conhecimento, comportamento, linguagem, ela se dá em aspectos perigosos, nocivos como a criminalidade, exploração sexual, violência, criminalidade, drogas, álcool. Cada dia que passa nos impressionamos e espantamos mais com o aumento do número de crianças que se envolvem e praticam roubos, assassinatos, estupros, tráfico de drogas, dentre outras transgressões. Prova disso é o que se discute, a todo o momento, no Brasil, a diminuição da idade penal ou a responsabilização das crianças com cada vez 
menos idade, pois elas acabam imitando as ações criminais da vida adulta. $\mathrm{O}$ mundo do adulto parece ter sido muito efetivo em invadir o espaço infantil ou trazer as crianças para o outro lado. Como diz Javeau (2005), expulsá-los do jardim da infância. Cabe a nós lançar questões sobre a educação desde a infância e ao longo da vida, para resgatar uma velada opção emancipadora e transformadora de vidas, que passa pelas contradições humanas da cultura da infância (coercitiva, roubada ou explorada por meio da uniformização homogênea de forma superficial e estereotipada) que a engendraram, e prevê uma conectividade na diferença e na solidariedade.

Essa discussão suscita uma nova lógica na qual os pais e professores tornam-se cada vez menos sapiens e a informação e opiniões midiáticas ganham mais força e espaço. (SIBILIA, 2012). Os pais e a escola vão perdendo aquela autoridade que se sustentava no domínio de um saber que hoje se encontra em outras plataformas que podem ser acessadas pela criança sem o auxílio dos adultos. Este saber produz novas subjetividades, novos comportamentos e novos jeitos de ser que conflitam com o pensamento do adulto formado em outro paradigma. $\mathrm{O}$ questionamento que surge a respeito de como organizar as práticas pedagógicas e de qual o papel do professor neste novo cenário habitado por crianças com estas características? Consideramos pertinente a hipótese de que a sociedade contemporânea procura de toda forma evitar a experiência da infância, o que quer dizer evitar ou abrir mão do papel pedagógico, crítico e estimulador da construção conjunta, cumprindo a função de sermos articuladores e mediadores dos significados produzidos na situação do cotidiano escolar.

Para evitar o abandono do compromisso e da responsabilidade com a infância e o trabalho artesanal que esse tempo requer, que não se restringe ao campo dos objetos ou da vida material, invade o mais íntimo dos sentimentos das pessoas, instala-se nas relações, orienta a vida privada, precisamos olhar e compartilhar experiências com as crianças na esfera educacional, cujo dinamismo e apelos do presente impõem-se como necessários para sua libertação e abertura, lançando luzes às problemáticas do passado. $\mathrm{O}$ campo da educação não tem ficado imune das razões políticas, históricas, sociais e culturais, o que nos leva a afirmar que os contextos educacionais estão cada vez mais vinculados ao discurso econômico da eficiência, da competitividade, da intensificação do mundo do trabalho e da hiperaceleração da vida cotidiana. Tal evidência nos remete, enquanto educadores, à reflexão sobre o sentido do nosso trabalho na escola e das alternativas existentes para fazer o enfrentamento desta lógica fatalista e da subsumida neutralidade praticada pelos professores nas atividades que faz retroceder a experiência da infância. Contudo, a reinvenção da infância implica na capacidade de reaprender a brincar, a dialogar, de parar para ouvir a voz da criança, de aprender o seu mundo e criar mais espaços compartilhados com a cultura infantil, para gerar processos inventivos e não homogêneos a partir das marcas e tempos da infância, recuperando também a experiência formativa do que há de humano em nós. 


\section{REFERÊNCIAS}

AGOSTINHO, S. Confissões. São Paulo: Paulus, 1997.

ANDRADE, L. B. P. Educação infantil: discurso, legislação e práticas institucionais [online]. São Paulo: UNESP; Cultura Acadêmica, 2010. Disponível em: <http://books.scielo.org>. Acesso em: 18 jul. 2018.

ARIÈS, P. História social da criança e da família. Rio de Janeiro: LTC, 1981.

BARBOSA, M. C. S. Fragmentos sobre a rotinização da infância. Educação \& Realidade, Porto Alegre, v. 25 n. 1, p. 93-113, jan./jun. 2000.

BAUMAN, Z. Tempos Líquidos. Rio de Janeiro: Jorge Zahar, 2007.

BAUMAN, Z. Vida para o consumo: a transformação das pessoas em mercadoria. Rio de Janeiro: Jorge Zahar, 2008.

BONA, V. de. Tecnologia e infância: ser criança na contemporaneidade. 2010. $144 \mathrm{f}$. Dissertação (Mestrado em educação) - Universidade Federal de Pernambuco, Recife, 2010.

BRASIL. Ministério da Educação e do Desporto. Secretaria de Educação Fundamental. Referencial Curricular Nacional para a educação infantil. Brasília, DF: MEC; SEF 1998. 3 v. (Introdução, v. 1; Formação pessoal e social, v. 2; Conhecimento de mundo, v. 3).

BRASIL. Ministério da Educação. Secretaria de Educação Básica. Diretoria de Apoio à Gestão Educacional. Pacto Nacional pela alfabetização na idade certa. Brasília: MEC; SEB, 2015. (A criança no ciclo de alfabetização, caderno 02).

BUJES, M. I. E. Infância e risco. Educação \& Realidade, Porto Alegre, v. 35, n. 3, p. 157-174, set./dez. 2010.

CAMBI. F. História da pedagogia. Trad. Álvaro Lorencini. São Paulo: UNESP, 1999.

COREA, C.; LEWKOWICZ, I. ¿Se acabó la infancia? Ensayo sobre la destitución de la niñez. Buenos Aires, Argentina: Lumen-Humanitas, 1999.

FARIA, A. L. G.; DEMARTINI, Z. B. F.; PRADO, P. D. Por uma cultura da infância: metodologias de pesquisa com crianças. São Paulo: Autores Associados, 2005.

FERREIRA, M. Do "avesso" do brincar ou... as relações entre pares, as rotinas da cultura infantil e a construção da (s) ordem(ens) social(ais) instituinte (s) das crianças no jardimde-infância. In: SARMENTO, M. J.; CERISARA, A. B. (Org.). Crianças e miúdos: perspectivas sociopedagógicas da infância e educação. Santa Rita de Azóia, Portugal: ASA, 2004. 
Artigo

doi: $10.20396 /$ rho.v18i3.8652022

FRIEDMANN, A. O olhar antropológico por dentro da infância: adentrando nas casinhas das crianças. In: MEIRELES, R. (Org.). Território do brincar: diálogo com escolas. São Paulo: Instituto Alana, 2015.

GHIRARDELLI JUNIOR, P. As concepções de infância e as teorias educacionais modernas e contemporâneas. Educação \& Realidade, Porto Alegre, v. 25, n. 1, p. 45-58, jan./jun. 2000.

JAVEAU, C. Criança, infância (s), crianças: que objetivo dar a uma ciência social da infância? Educação e Sociedade, Campinas, v. 26, n. 91, p. 379-389, maio/ago. 2005.

KOHAN, W. O. Vida e morte da infância, entre o humano e o inumano. Educação \& Realidade, Porto Alegre, v. 35, n. 3, p. 125-138, set./dez. 2010.

KRAMER, S. A política do pré-escolar no Brasil: a arte do disfarce. São Paulo: Cortez, 1995.

LYOTARD, J. O Pós-Moderno. Rio de Janeiro: José Olympio, 1986.

MARÍN-DIAZ, D. L. Morte da infância Moderna ou construção da quimera infantil?

Educação e Realidade, Porto Alegre, v. 35, n. 3, p. 193-211, set./dez. 2010.

MARTINS FILHO, J. Quem cuidará das crianças? A difícil tarefa de educar os filhos hoje. Campinas, SP: Papirus, 2011.

MUNIZ, L. Naturalmente criança: a educação infantil de uma perspectiva sociocultural. In: KRAMER, S. et al. (Org.). Infância e educação infantil. 6. ed. Campinas, SP: Papirus, 1999. p. 243-268.

PINHEIRO, M. M. Concepções de infância e educação infantil que permeiam a prática docente. 2008. 122 f. Dissertação (Mestrado em Educação) - Universidade Federal do Rio Grande do Norte, Natal, 2008.

PINTO, M.; SARMENTO, M. J. (Coord.). As crianças: contextos e identidades. Braga: Universidade do Minho, 1997.

PLATÃO. Diálogos. São Paulo: Abril Cultural, 1996.

POSTMAN, N. O desaparecimento da infância. Rio de Janeiro: Graphia, 1999.

QVORTRUP, J. A infância enquanto categoria estrutural. Educação e Pesquisa, São

Paulo, v. 36, n. 2, p. 631-643, maio/ago. 2010. Disponível em:

<http://www.revistas.usp.br/ep/article/view/28253>. Acesso em: 03 nov. 2015.

ROUSSEAU, J. Emílio ou da educação. Tradução Sérgio Milliet. 3. ed. Rio de Janeiro: Bertrand Brasil, 1995. 
SIBILIA, P. Redes ou paredes: a escola em tempos de dispersão. Rio de Janeiro:

Contraponto, 2012.

Notas

${ }^{1}$ Docente, pesquisador e Reitor da Universidade Regional do Alto Uruguai e das Missões - URI. E-mail: narnaldo@uricer.edu.br

${ }^{2}$ Docente e pesquisadora da Universidade La Salle - Unilasalle. E-mail: hildegard.jung @ unilasalle.edu.br

${ }^{3}$ Docente e pesquisadora da Universidade La Salle - Unilasalle. E-mail: elaine.conte@ unilasalle.edu.br

${ }^{4}$ Disponível em: http://goo.gl/Ss64Yx. Acessado em out. 2016. Trata-se de uma produção de Maria Farinha Filmes, lançada em 05 de maio de 2016.

Submetido em: $25 / 03 / 2018$

Aprovado em: 22/07/2018

Publicado em: 28/09/2018 